\title{
A REVIEW OF TRABECULECTOMIES AT A NIGERIAN TEACHING HOSPITAL
}

\author{
*B. O. ADEGBEHINGBE and T. MAJEMGBASAN \\ Ophthalmology Unit, Department of Surgery, College of Health Sciences, Obafemi Awolowo University, Ile- \\ Ife, Osun State, Nigeria
}

\begin{abstract}
SUMMARY
Background: Trabeculectomy is the commonest surgical procedure for glaucoma. The outcome of trabeculectomy in the treatment of all types of glaucoma over a 4-year period in a Nigerian population was re-
\end{abstract} viewed.

Objective: To determine the surgical rate and effectiveness of trabeculectomy in lowering of intra ocular pressure (IOP) and preservation of visual acuity.

Methods: Retrospective review of all trabeculectomies (TEs) done at the Obafemi Awolowo University Teaching Hospital, Ile-Ife between January 1999 and December 2002. The outcome of trabeculectomy was correlated with the biomicroscopic appearance of the filtering bleb, visual acuity and IOP levels. Descriptive statistics were applied to the data.

Results: Of the 647 glaucoma patients only fifty-three (8.2\%), 34 males and 19 females, had trabeculectomy done during the study period. Seventy-two consecutive eyes of these 53 Nigerian patients were operated upon. Majority, 63 (87.5\%) were in the primary glaucoma group of which 46 (63.9\%) were open angle glaucoma type. Nine eyes $(12.5 \%)$ belonged to the secondary glaucoma group (neovascular, uveitic and traumatic angle recession). Successful control of intra-ocular pressure with medical therapy was recorded only in $13.9 \%$ of the patients. The mean pre-operative and first post-operative day IOP were $32.5+/-6.2 \mathrm{mmHg}$ and $10.6+/-2.3 \mathrm{mmHg}$ respectively. Mean post-op IOP at 3 months and one year were $14.6+/-4.2 \mathrm{mmHg}$, and $13.5+/-5.8 \mathrm{mmHg}$ respectively. One year after surgery 34 eyes (61.8\%) had intraocular pressure (IOP) of $20 \mathrm{~mm} \mathrm{Hg}$ or less without glaucoma medication. Hyphema 11 (15.3\%) was the commonest post-operative complication documented.

Conclusions: Surgical intervention in the management of glaucoma, especially trabeculectomy is not commonly done in this Teaching Hospital. IOP control with medication alone is not adequate in the long term. A significant proportion of the eyes (61.8\%) had complete success in IOP control following trabeculectomy.
Key words: Glaucoma, Trabeculectomy, Intra-ocular pressure, Nigeria

\section{INTRODUCTION}

Medical treatment of glaucoma does not always succeed in lowering intra-ocular pressure (IOP) despite recent advances in medicines for glaucoma. As a result some patients will require surgery to preserve their vision. In developing countries, especially among blacks, surgical treatment of glaucoma is generally assumed to be preferable to medical treatment.,

Trabeculectomy is the most common non-laser surgical procedure for managing glaucoma. The goal of the surgery is to establish a permanent flow of aqueous from the anterior chamber to the sub-conjunctival space thereby lowering IOP.

Secondary glaucoma such as neo-vascular, uveitic, developmental, traumatic, aphakic and congenital glaucoma generally have a much poorer prognosis with filtering surgery and may require other treatment modalities. Even so, trabeculectomy is still the initial surgical intervention attempted in these cases. Anti-metabolites are known to play a positive role in lowering IOP significantly when used in filtration surgery but they can lead to serious complications. ${ }^{3}$

The primary aim of glaucoma management, including trabeculectomy, is to control intra-ocular pressure and preserve visual field. These two parameters must be closely monitored during the treatment of glaucoma. However, serial documentation and monitoring of visual field changes are not done for most patients due to lack of facility for the test.

This study retrospectively assessed the outcome of trabeculectomy performed at a teaching hospital with the aim of determining the effectiveness of the procedure in relation to IOP control.

\footnotetext{
${ }^{*}$ Corresponding author berniceola2003@yahoo.co.uk
} 


\section{METHODS}

We retrospectively reviewed all patients who underwent trabeculectomy at the Obafemi Awolowo University Teaching Hospital over a 4-year period, between January 1999 and December 2002. Data collected from their case notes included age, sex, eye involved, type of glaucoma, eye operated, pre-operative and postoperative visual acuity, intra-ocular pressure at presentation , pre-operatively and post-operatively ( day 1, day 2 , week 2, week 6 , week 12, month 6 and month 12). Information with regards to pre-operative antiglaucoma therapy, complications of surgery, postoperative anti-glaucoma medication and presence of a filtering bleb were recorded.

The technique of trabeculectomy was generally considered to be Watson's ${ }^{4}$ modification of Cairn's technique $^{5}$. A fornix based conjunctival flap was raised followed by tenectomy. A rectangular limbal based superficial sclera flap incision ( $5 \mathrm{x} 4 \mathrm{~mm}$ ) was dissected until the surgical limbus was seen. The trabeculectomy was then completed with a rectangular deep corneo-scleral block excision ( $3 \times 2 \mathrm{~mm})$. A peripheral iridectomy was performed before closing the superficial scleral flap with $8 / 0$ virgin silk; the conjunctival was also sutured with $8 / 0$ virgin silk. Subconjunctival gentamycin (20mg) and dexamethasone 10mg were injected into the inferior fornix, followed by topical chloramphenicol and atropine 1\% drops before the eye was padded. Post operative local antibiotic (Chloramphenicol), mydratics (cyclopentolate), and steroid drops were also applied.

Some patients were given 5-fluorouracil (5-FU) intraoperatively. After dissecting the superficial scleral flap the conjunctival and the superficial scleral flap were pulled over $4 \mathrm{mmx} 3 \mathrm{~mm}$ piece of weckcel sponge saturated with 5 -FU $(50 \mathrm{mg} / \mathrm{ml})$ for a total of 5 minutes. ${ }^{6,7}$ After the sponge was removed, the area was irrigated copiously with $50 \mathrm{ml}$ of normal saline. A peripheral iridectomy was made before closing the superficial scleral flap with $8 / 0$ virgin silk and the procedure completed as above.

Three consultant ophthalmic surgeons performed the surgeries using the same surgical techniques and management procedures.

The outcome of trabeculectomy was correlated with documented biomicroscopic appearance of the filtering bleb, visual acuity and IOP levels. The effect of 5Fluoro-uracil (5-FU) on complications, IOP lowering, and visual outcome was studied in 15 eyes. The outcome of the surgery was classified as complete success (post operative IOP at one year was $20 \mathrm{mmHg}$ or less without anti-glaucoma medication), qualified success (post-operative IOP was $20 \mathrm{mmHg}$ or less with additional anti-glaucoma medication) and failure (postoperative IOP was greater than $20 \mathrm{mmHg}$ in spite of maxima anti-glaucoma medication). ${ }^{1}$

Approval for the study was obtained from the Research and Ethics Committee of the Obafemi Awolowo University Teaching Hospital Complex, Osun State, Nigeria.

Frequency distribution tables were used to present the data. Categorical variables were summarized as proportions and percentages while the Chi-square test and ANOVA were used to compare the association between any two categorical variables. Mean and standard deviation were used for continuous variables. All test were two sided and at 5\% level of statistical significance.

\section{RESULTS}

A total number of 7910 new patients were seen over the five year period. Of these 647 (8.2 \%) had glaucoma. Fifty-three (8.2\%) patients consisting of 34 males and 19 females had glaucoma surgery (trabeculectomy) done during the study period. Male to female ratio was 1.8:1.

Table1 Age and Gender distribution of the 53 patients

\begin{tabular}{|c|c|c|c|}
\hline Age (yrs) & Male (\%) & $\begin{array}{c}\text { Female } \\
(\mathbf{\%})\end{array}$ & Total (\%) \\
\hline$\leq \mathbf{1 0}$ & $2(3.8)$ & $1(1.9)$ & $3(5.7)$ \\
\hline $\mathbf{1 1 - 2 0}$ & $1(1.9)$ & $0(0.0)$ & $1(1.9)$ \\
\hline $\mathbf{2 1 - 3 0}$ & $3(5.7)$ & $2(3.8)$ & $5(9.5)$ \\
\hline $\mathbf{3 1 - 4 0}$ & $5(9.5)$ & $3(5.7)$ & $8(15.2)$ \\
\hline $\mathbf{4 1 - 5 0}$ & $7(13.3)$ & $4(7.6)$ & $11(20.9)$ \\
\hline $\mathbf{5 1 - 6 0}$ & $9(17.1)$ & $7(13.3)$ & $16(30.4)$ \\
\hline $\mathbf{6 1 - 7 0}$ & $4(7.6)$ & $2(3.8)$ & $6(11.4)$ \\
\hline $\mathbf{7 1 - 8 0}$ & $2(3.8)$ & $0(0.0)$ & $2(3.8)$ \\
\hline$\geq \mathbf{8 1}$ & $1(1.9)$ & $0(0.0)$ & $1(1.9)$ \\
\hline Total & $\mathbf{3 4}(\mathbf{6 4 . 2})$ & $\mathbf{1 9}(\mathbf{3 5 . 8})$ & $\mathbf{5 3 ( 1 0 0 . 0 )}$ \\
\hline
\end{tabular}

The patients' age range was 5 months to 86 years, while mean age +/-SD was $43.5+/-3.5$ years. Age and gender distribution of the patients is as shown in Table 1.

Out of the 72 consecutive eyes of the 53 patients operated upon, 63 (87.5\%) eyes in 44 patients were in the primary glaucoma group. Forty-six eyes (63.9\%) of 35 patients (22 males and 13 females) were open angle glaucoma type. Others were primary angle closure glaucoma type, $12(16.7 \%)$ eyes in 6 patients, normotensive glaucoma group $3(4.2 \%)$, and congenital glaucoma 2 (2.8\%). Nine eyes $(12.5 \%)$ belonged to the secondary glaucoma group: neo-vascular 2 (2.8\%), 
uveitic 2 (2.8\%) and traumatic angle recession 5 (6.9\%). There was a statistically significant male preponderance in the number of patients with chronic open angle glaucoma $(\mathrm{p}=0.001,95 \% \mathrm{CI})$ as opposed to that of angle closure glaucoma in which there were predominantly females ( $\mathrm{p}=0.013,95 \% \mathrm{CI})$.

5-FU was used in 15 eyes of 14 (26.4\%) patients consisting of the 9 eyes with secondary glaucomas and 6 randomly selected eyes with primary open angle glaucoma. However, 57 eyes of 39 patients (73.59\%) consisting of 46 eyes with primary open angle glaucoma (POAG) and 11 eyes with primary angle closure glaucoma (PACG) had non-5FU augmented trabeculectomy.

Among the non 5FU-augmented patients, the presenting IOP ranged from 21 to 56 with a mean of $30.7+/-$ $8.5 \mathrm{mmHg}$. The mean pre-operative IOP was $32.5+/-$ $6.2 \mathrm{mmHg}$. An IOP of $30 \mathrm{mmHg}$ or more was seen in 37 eyes $(64.9 \%)$ at presentation but only in 13 eyes (22.8\%) after medical treatment. IOP of $21 \mathrm{mmHg}$ or more was present in 57 eyes at presentation but in 47 eyes (82.5\%) after medical treatment. Successful control of intra ocular pressure with medical therapy was recorded only in 10 (17.5\%) eyes.

Overall, the mean IOP at the first post operative day was $10.6+/-2.3 \mathrm{mmHg}$. On the second post-operative day, 34 eyes (59.6\%) had a post-operative IOP of $15 \mathrm{mmHg}$ or less while 6 eyes (10.5\%) had an IOP of $21 \mathrm{mmHg}$ or more. At 3 months the post operative IOP ranged from $7-32 \mathrm{mmHg}(16.8+/-7.2 \mathrm{mmHg})$. At 12 months the post-operative IOP ranged between 10 and $28 \mathrm{mmHg}$, with a mean of $16.2+/-3.7 \mathrm{mmHg}$. Only 7 eyes $(12.3 \%)$ had an IOP of $21 \mathrm{mmHg}$ or more at 12 months post operative visit.

Complete success was obtained in 48 eyes (84.7\%) at 3 months, $41(70.7 \%)$ at 6 months, and 34 eyes (61.8\%) at 12 months in the non-augmented group. Qualified success was seen in 15 (27.3\%) while the failure rate was 6 (10.9\%) 12 months after surgery.

The mean post-operative IOP in 15 eyes with 5FUaugmented trabeculectomy was $(9.4 \pm 3.2 \mathrm{mmHg}$ at 48hours, $11.7 \pm 5.2 \mathrm{mmHg}$ at 3 months and $14.3 \pm$ $6.5 \mathrm{mmHg}$ at $1 \overline{2}$ months. The mean post-operative IOP in the 5FU-augmented cases was significantly lower compared with the non augmented cases $(\mathrm{P}=0.0005$, 95\% C.I). At 1 year follow-up 11 (73.3\%) had complete success (post-operative IOP $\leq 21 \mathrm{mmHg}$ ).

Table 2 shows the comparison of preoperative and postoperative visual acuity (VA). Preoperative and postoperative VA of $6 / 18$ or less was found in $93 \%$ of the eyes and $86.7 \%$ respectively. There were no significant changes in the VA during the follow-up period.

Table 2 Comparison of pre-operative and postoperative visual acuity at 3months

\begin{tabular}{|c|c|c|}
\hline Visual Acuity & $\begin{array}{c}\text { Pre-operative } \\
\text { No. eyes (\%) }\end{array}$ & $\begin{array}{c}\text { Post-operative } \\
\text { No. eyes (\%) }\end{array}$ \\
\hline $\begin{array}{c}\text { Light percep- } \\
\text { tion }\end{array}$ & $0(0.0)$ & $0(0.0)$ \\
\hline Finger counting & $0(0.0)$ & $3(5.0)$ \\
\hline $\mathbf{6 / 6 0}$ & $12(16.7)$ & $10(16.7)$ \\
\hline $\mathbf{6 / 3 6}$ & $29(40.3)$ & $15(25.0)$ \\
\hline $\mathbf{6 / 2 4}$ & $19(26.4)$ & $17(28.3)$ \\
\hline $\mathbf{6 / 1 8}$ & $7(9.7)$ & $7(11.7)$ \\
\hline $\mathbf{6 / 1 2}$ & $3(4.2)$ & $5(8.3)$ \\
\hline $\mathbf{6 / 9}$ & $2(2.8)$ & $3(5.0)$ \\
\hline Total & $\mathbf{7 2 ( 1 0 0 . 0 )}$ & $\mathbf{6 0}(\mathbf{1 0 0 . 0})$ \\
\hline
\end{tabular}

Bleb formation was good and diffuse away from the limbus in $40(72.7 \%)$ of the eyes while cystic bleb was seen in $6(10.9 \%)$ and flat bleb in $9(16.4 \%)$ of the eyes at one year follow-up. About $80 \%$ of those with modified success had either a flat or cystic bleb. A significant proportion of those with cystic and flat blebs had poorly controlled IOP ( $p=0.0012$, 95\% C.I).

Table 3 shows the age distribution of the outcome of surgery in relation to IOP control. There is no statistical significant relationship between the surgical success rate and the age of the patients.

Table 3 Outcome of surgery by number of eyes in different age groups at 1 year in un-augmented cases

\begin{tabular}{|l|l|l|l|}
\hline $\begin{array}{l}\text { Age } \\
\text { (Yrs) }\end{array}$ & $\begin{array}{l}\text { Complete } \\
\text { success } \\
\text { No. (\%) }\end{array}$ & $\begin{array}{l}\text { Qualified } \\
\text { success } \\
\text { No. (\%) }\end{array}$ & $\begin{array}{l}\text { Failure } \\
\text { No. (\%) }\end{array}$ \\
\hline$\leq \mathbf{1 0}$ & $0(0.0)$ & $4(7.2)$ & $0(0.0)$ \\
\hline $\mathbf{1 1 - 2 0}$ & $0(0.0)$ & $2(3.6)$ & $0(0.0)$ \\
\hline $\mathbf{2 1 - 3 0}$ & $2(3.6)$ & $2(3.6)$ & $1(1.8)$ \\
\hline $\mathbf{3 1 - 4 0}$ & $6(10.9)$ & $1(1.8)$ & $1(1.8)$ \\
\hline $\mathbf{4 1 - 5 0}$ & $7(12.7)$ & $3(5.4)$ & $1(1.8)$ \\
\hline $\mathbf{5 1 - 6 0}$ & $13(23.6)$ & $3(5.4)$ & $0(0.0)$ \\
\hline $\mathbf{6 1 - 7 0}$ & $4(7.2)$ & $0(0.0)$ & $2(3.6)$ \\
\hline$\geq \mathbf{7 1}$ & $2(3.6)$ & $0(0.0)$ & $1(1.8)$ \\
\hline Total & $\mathbf{3 4}(\mathbf{6 1 . 8 )}$ & $\mathbf{1 5 ( 2 7 . 3 )}$ & $\mathbf{6 ( 1 0 . 9 )}$ \\
\hline
\end{tabular}

Hyphema 11 (15.3\%) was the commonest early postoperative complication documented. Others were shallow anterior chamber (AC), ocular hypotony, elevated IOP, and cataract; each occurring in 4 (5.5\%) and choroidal detachment in 2 (2.8\%). Late post operative complications documented were bleb failure in 6 eyes (8.4\%), cataract $2(2.8 \%)$ and encapsulated bleb 1 (1.4\%). 


\section{DISCUSSION}

Trabeculectomy is the most common operative procedure for the treatment of medically uncontrolled glaucoma. It remains the mainstay of treatment for black glaucoma patients especially those of African origin due to the unavailability and high cost of topical therapy. The proportion of glaucoma patients (8.2\%) that had surgery in this report is very low, the reasons for this `could not be ascertain in this retrospective study. Previous studies reported that the reasons are multifactorial; however, the most significant one was poor acceptability of the procedure among glaucoma patients. ${ }^{1,7}$

In this study there was male preponderance among those who had trabeculectomy done but this was not statistically significant $(p=0.08)$. This is similar to the findings of Mielke and others in their study conducted in Lagos, Nigeria where no significant difference was found in the age distribution of patients who had unaugumented trabeculectomy ${ }^{6}$ but at variance with that of Bekibele in Ago-Iwoye, Nigeria.

In this study, those patients that had intra-operative anti-metabolite had a significant higher success rate when compared with those who did not have. The complete success rate at twelve months was (61.8\%) in those who had unaugmented surgery and $73.3 \%$ in the augmented cases. Gonzalez et al found a complete success rate of $79 \%$ at 4 months, $77.5 \%$ at 6 months, $75 \%$ at 8 months and $61 \%$ at 12 months during a review of the effect of 5-FU on trabeculectomy among Nigerians. ${ }^{8}$ Trabeculectomy without anti-metabolite use appears to be an effective way to lower the IOP in glaucoma patients but the use of intra-operative 5-FU during trabeculectomy was found to improve the probability of maintaining a much lower intra-ocular pressure. This is also in agreement with findings in previous studies. ${ }^{1,6,9}$ Trabeculectomy tends to fail over time because of the fibroblastic proliferation and subconjunctival fibrosis which occurs during the normal process of wound healing. ${ }^{10,11}$ Adjunctive use of antifibrotic agents such as mitomycin $\mathrm{C}$ or 5 -fluorouracil at the site of surgery has significantly reduced the risk of bleb failure. ${ }^{12,13}$

Filtering procedures are associated with failures in the blacks owing to their propensity for increased fibrosis. Reports of favorable results are those from modifications of standard techniques such as non-suturing of flaps, sclerectomy, posterior lip cautery, or administration of high doses of steroids. However, 95.4\% success with a virtual absence of complications had been reported from a standard technique of trabeculectomy. ${ }^{9}$ Trabeculectomy still remain the most effective for cases of uncontrolled primary open-angle glaucoma, closed-angle glaucoma, exfoliation syndrome and pigmentary glaucoma. The secondary glaucomas such as neovascular, uveitic, developmental, traumatic, and aphetic generally have a much poorer prognosis with filtering surgery and may require other treatment modalities. Even so, a trabeculectomy is still the initial surgical intervention attempted in these cases.

The most significant outcome was the presence of a diffuse filtering bleb. The diffuse filtering bleb type was associated with the greatest decrease in IOP. Similar finding was reported by previous workers. ${ }^{1,6,10}$ Surgical failure was associated with flat and nonfunctioning bleb as reported in other studies. ${ }^{14,15}$

Trabeculectomy was not associated with any significant visual loss in this study. Visual loss of more than two Snellen -chart lines was observed in a significant proportion of patients who had primary trabeculectomy in a Nigerian population. ${ }^{8}$ Bekibele found a statistically significant decrease in visual acuity post-operatively. ${ }^{6}$

Complications in this study were mainly transient and have no permanent visual sequelae. The most common being hyphema in 11 eyes (15.3\%).Those who had shallow anterior chamber following trabeculectomy (5.5\%) were treated conservatively with the use of mydratics and firm padding. Wound leak or excessive filtration was responsible for this. Though bleb leaks can be managed conservatively; in other instances, surgical repair is necessary. Fortunately, there was no sustained severe shallow anterior chamber in any of the patients as all were re-formed spontaneously following the conservative management. The 4 eyes which developed post operative cataract subsequently had cataract surgery. Elevated IOP was found to be due to malignant glaucoma in one of the patients. Pressure in this patient reduced significantly with intense papillary dilation using atropine, mydracil and phenylepherine $10 \%$ in addition to systemic (acetazolamide) and topical (timolol 0.5\%) anti-glaucoma therapy.

Late complications such as bleb failure and encapsulated bleb were successfully managed as well. The encapsulated bleb had needling of the bleb with subconjunctival 5-FU injection using the Allen et al. method. ${ }^{14}$ Early bleb failure is also possible as well as other potential complications such as choroidal effusions, and formation of a Tenon cyst. Any of these can affect the final outcome of the surgery if not appropriately treated.

The presence of a filtering bleb poses a continuing risk of infection over a patient's lifetime. ${ }^{16-19}$ One of the most serious complications after glaucoma filtering 
surgery is infection. This may represent a limited form or early stage of endophthalmitis. ${ }^{6}$ Blebitis and endophthalmitis had been documented potential complications of trabeculectomy ${ }^{20,21}$ but were not seen in this particular study.

\section{CONCLUSION}

This study revealed that trabeculectomy, though sparingly done, was associated with significantly high success rates (complete success rates in unaugmented and augmented cases were $61.8 \%$ and $73.3 \%$ respectively). Although the type of glaucoma influences the outcome of trabeculectomy, this study was not designed to relate the outcome of surgery to the different types of glaucoma. Presence of a diffuse bleb was a good indicator of controlled intra-ocular pressure. There was no statistical significant decrease in visual acuity postoperatively. The intra-operative and post-operative complications were mostly transient, minimal and nonconsequential. The factors which affect uptake of glaucoma surgery in the teaching hospital should be further studied with the aim of improving the surgical rate.

\section{REFERENCES}

1. Agbeja-Bayeroju AM, Omoruyi M, Owoaje ET. Effectiveness of trabeculectomy on glaucoma patients in Ibadan. Afr J Med Sci 2001; 31: 39-42

2. Jay JL and Allan D. The benefit of early trabeculectomy versus conventional management in primary open angle glaucoma relative to severity of disease. Eye 1989; 3: 528-535.

3. Pojda SM, Herba E, Zatorska B, et al. The longterm follow-up after trabeculectomy. Klin Oczna. 2001; 103(4-6):161-4.

4. Watson PG. Trabeculectomy: A modified ab- externo technique. Ann Ophthamol 1970; 2: 199-205.

5. Cairn's JE. Trabeculectomy: Preliminary report of a new method. Am J Ophthmol 1968; 66:673-679.

6. Mielke C, Dawda VK, Anand N. Intra-operative 5fluorouracil application during primary trabeculectomy in Nigeria: a comparative study. Eye. 2003; 17(7): 829-34.

7. Bekibele CO. Evaluation of 56 trabeculectomy operations at Ago- Iwoye, Ogun state, Nigeria. West Afr J Med 2001; 20(3): 223-6.

8. Gonzalez BJ, Gonzalez MI, Gonzalez GM, Marin R, Varas A, Montesinos TM. Non-penetrating deep trabeculectomy treated with mitomycin C without implant. A prospective evaluation of 55 cases. J Fr Ophthamol 2004 Oct; 27(8): 907-11.

9. Thommy CP, Bhar IS. Trabeculectomy in Nigerian patients with open-angle glaucoma. $\mathrm{Br} J$ Ophthalmol 1979 Sept; 63(9): 636-42.

10. Agbeja-Bayeroju Am, Owoaje ET, Omoruyi M. Trabeculectomy in young Nigerian patients. Afr $J$ Med Sci 2002 Mar;31(1): 33-5.

11. Skuta GL. Wound healing in glaucoma filtering surgery. Surv Ophthalmol 1987; 32: 139-170.

12. Singh J, O’Brien C, Chawle HB. Success rates and complications of intra-operative $0.2 \mathrm{mg} / \mathrm{ml}$ mitomicin in trabeculectomy surgery. Eye 1995; 9:460466.

13. Greenfield DS, Liesmann JM, Jee J, Ritch R. Late onset bleb leaks after glaucoma filtering surgery. Arch Ophthalmol 1998; 116:443-447.

14. Allen LE, Mannchehri K, Corridan PG. The treatment of encapsulated trabeculectomy blebs in an out-patient setting using a needling technique and subconjunctival 5-fluorouacil injection. Eye 1998; 12: $119-123$

15. DeBry PW, Perkins TW, Heatley G, et al. Incidence of late-onset bleb-related complications following trabeculectomy with mitomycin. Arch Ophthalmol 2002; 120:297-300.

16. Brown RH, Yang LH, Walker SD, et al. Treatment of bleb infection after glaucoma surgery. Arch Ophthalmol 1994; 112:57-61.

17. Mochizuki K, Jikihara S, Ando Y, et al. Incidence of delayed onset infection after trabeculectomy with adjunctive mitomycin $\mathrm{C}$ or 5-fluorouracil treatment. Br J Ophthalmol 1997; 81:877-883.

18. Soltau JB, Rothman RF, Budenz DL et al. Risk factors for glaucoma filtering bleb infections. Arch Ophthalmol 2000; 118:338-342.

19. Lehmann OJ, Bunce C, Matheson MM, et al. Risk factors for development of post-trabeculectomy endophthalmitis. Br J Ophthalmol 2000; 84:13491353.

20. Ciulla TA, Beck AD, Topping TM, et al. Blebitis, early endophthalmitis, and late endophthalmitis after glaucoma-filtering surgery. Ophthalmology 1997; 104:986-995.

21. Poulsen EJ and Allingham RR. Characteristics and risk factors of infections after glaucoma filtering surgery. $J$ of Glaucoma 2000; 9:438-443. 